\title{
RHEOLOGICAL PROPERTIES OF PALYGORSKITE-SMECTITE SUSPENSIONS FROM THE VENTZIA BASIN, W. MACEDONIA, GREECE
}

\author{
Christidis, G.E. ${ }^{1}$ Katsiki, P. ${ }^{1}$ Pratikakis, A. ${ }^{1}$ and Kacandes, G. ${ }^{\mathbf{2}}$ \\ ${ }^{1}$ Technical University of Crete, Department of Mineral Resources Engineering, 73100 Chania, Greece, \\ christid@mred.tuc.gr,apratik@mred.tuc.gr, \\ ${ }^{2}$ Geohellas SA, 60 Zephyrou st \& Syngrou Av.17564 Athens, Greece, gkacandes@geohellas.gr
}

\begin{abstract}
In this contribution we examine the rheological properties of palygorskite rich clays from the Ventzia Basin, W. Macedonia, Greece. The clays consist of palygorskite and/or dioctahedral Fe-rich smectite (nontronite) and quartz as main components, and serpentine, amphibole and sepiolite as minor constituents. The apparent and plastic viscosity and yield point increase with increasing concentration of clay in the suspension. Flow is Newtonian for $1 \%$ suspensions, becoming gradually Bingham plastic (3\% clay suspensions) and then pseudoplastic with yield point described by the Herschel Bulckley flow model. In the case of suspensions of smectite-free clays Bingham plastic flow behaviour was not observed. Addition of $1 \mathrm{M} \mathrm{NaCl}$ electrolyte deteriorates the rheological behaviour of the smectite-bearing palygorskite clays but it does not affect significantly the smectite-free, palygorskite rich clays. The different rheological properties of the palygorskite compared to smectite is due to the different morphological and crystal-chemical properties of these two minerals. It is suggested that the palygorskite-rich clays can be used successfully as drilling muds in seawater based drilling fluids, in which smectite-based drilling muds tend to flocculate.
\end{abstract}

Key words: palygorskite, nontronite, viscosity, yield point, electrolyte, Herschel Bulckley flow, Ventzia Basin, W. Macedonia.

\section{Introduction}

Palygorskite is an Mg-rich clay mineral, forming crystals with characteristic fibrous or lath-like habit, which is attributed to their ribbon-like structure. It is considered special clay characterized by microfibrous morphology (Murray, 2007). The term attapulgite is often used as synonymous to palygorskite, although it is not recommended by the nomenclature committee of AIPEA. In the USA the term fuller's earth, which describes sorptive clays includes also palygorskite rich clays, although in the UK this term describes mainly Ca-rich bentonites.

The rheological properties of suspensions of industrial clays such as bentonites and kaolins have been studied extensively in the past and it is well known that it is affected by particle size and shape, clay concentration, type of exchangeable cation, $\mathrm{pH}$, electrolyte concentration and layer charge (Heath and Tadros, 1983; Brandenburg and Lagaly, 1988; Lagaly, 1989; Permien and Lagaly, 1995; Keren, 1988; 1989). In contrast the rheological properties of palygorskite suspensions have been studied to a lesser degree. In a limited number of studies it has been established that the type of ad- 


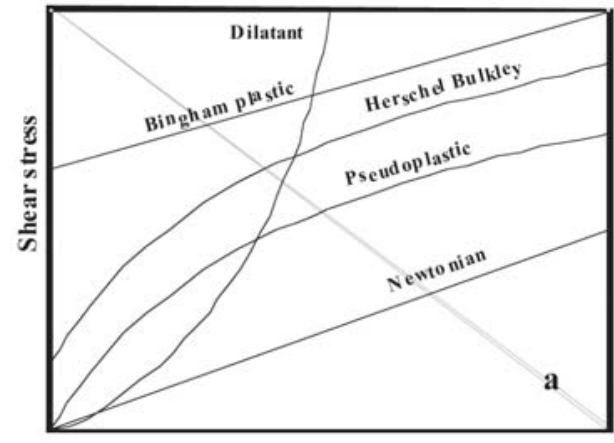

Shear rate

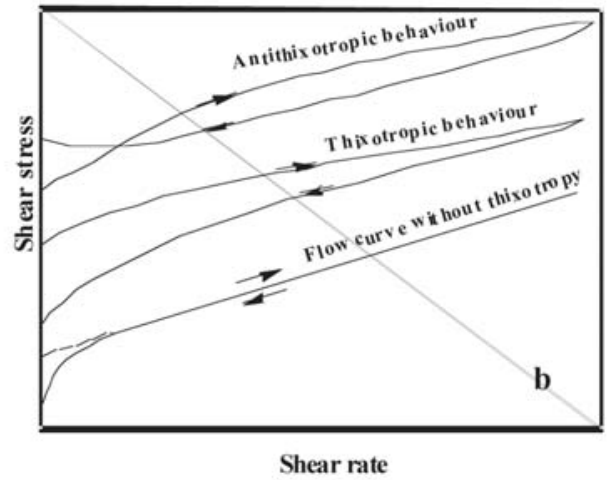

Shear rate

Fig. 1: a) Different types of flow curves observed in clay suspensions. b) Typical flow curves for concentrated thixotropic clay suspensions.

Table 1. Rheological models which describe the rheological behaviour of clay suspensions

\begin{tabular}{|l|l|l|}
\hline Type of suspension & Equation & Type of flow \\
\hline Newtonian & $\tau=\eta \gamma$ & Newtonian \\
Bingham Plastic & $\tau=\tau_{\beta}+\eta_{\mathrm{pl}} \gamma$ & Plastic \\
Power low & $\tau=\mathrm{K} \gamma^{\eta}$ & Shear thickening or shear thinning \\
Herschel-Bulkley & $\tau=\tau_{\mathrm{y}}+\mathrm{K} \gamma^{\eta}$ & Shear thinning or shear thickening \\
\hline Where $\eta=$ viscosity, $\tau=$ shear stress, $\gamma=$ shear rate, $\tau \beta=$ Bingham yield stress and $\tau p l=$ plastic viscosity. \\
In the Herschel Bulkley (HB) model, $\tau y=\mathrm{HB}$ yield stress and $\mathrm{K}=\mathrm{HB}$ consistency index \\
\hline
\end{tabular}

sorbed ions, $\mathrm{pH}$, clay concentration, fibre length and electrolyte addition influence the rheological properties of a series of palygorskite suspensions (Neaman and Singer, 2000; 2004)

In this contribution we study the rheological properties of a series of palygorskite-rich samples from a palygorskite deposit which was recently discovered in Ventzia Basin, Western Macedonia (Kastritis et al., 2003). The deposit formed in a lacustrine environment and displays zonation, with palygorskite occurring at the centre of the basin. Palygorskite is Fe-rich and formed via diagenetic alteration of detrital smectite which originated from the nearby ophiolite complex of Vourinos and the smectite-bearing sands of the Mesohellenic trench (Kastritis et al., 2003). The parameters which were examined are the clay concentration and electrolyte addition. We also examined the influence of smectite in the rheological properties of the suspensions.

\section{Theoretical background}

Clays are often used in suspensions. For example suspensions of kaolins are used in the slip casting processes during the manufacture of ceramics and in coating paper, whereas smectite and palygorskite are used in drilling fluids. In these applications the flow properties of the suspensions are of primary importance. The science of the deformation and flow of matter is known as rheology (Hiemenz \& Rajagopalan, 1997). The viscosity of a liquid is a measure of the internal resistance offered to the relative motion of different parts of a liquid. Clay suspensions can display Newtonian, Bingham plastic, shear thickening (dilatant) or shear thinning (pseudoplastic) behaviour and may develop yield stress (Fig. 1) (Lyckham \& Rossi, 1999). The equations which describe the rheological 
behaviour of various types of suspensions are shown in Table 1. Moreover they can develop timedependent phenomena such as thixotropic or rheopectic (antithixotropic) behaviour (Brandenburg \& Lagaly, 1988; Lagaly, 1989; Lyckham \& Rossi, 1999) (Fig. 1b). The term thixotropy refers to the ability of a suspension to form a gel upon standing and to become fluid when subjected to shear stress i.e. under stirring or agitation.

\section{Sampling and experimental methods}

Ground palygorskite-rich clayey samples were obtained from Geohellas SA. The received powders were less than $75 \mu \mathrm{m}$ in size. Bulk mineralogy was determined by X-ray powder diffraction (PXRD) (Siemens D500, CuKa radiation, graphite monochromator, $35 \mathrm{kV}$ and $35 \mathrm{~mA}$, using a $0.02^{\circ}$ step size and 1 second per step counting time), on randomly oriented samples, which had been previously gently ground with pestle and mortar in acetone. After grinding the samples were dried at $60^{\circ} \mathrm{C}$. The final particle size of the powders was $\sim 10 \mu \mathrm{m}$. According to the type of clay mineral present (palygorskite or/and smectite) the clay samples were classified in three groups: clays containing only palygorskite, clays containing only smectite and clays with both minerals.

In as much as only one sample was palygorskite-free, experiments were focused on determination of the rheological properties of clay suspensions of samples containing palygorskite and palygorskite + smectite. Rheological properties (apparent viscosity, plastic viscosity, yield point) were determined with a Couette-type Fann $35 \mathrm{~S}$ viscometer at $20^{\circ} \mathrm{C}$ according to the API specifications (API 13A, 1993). Fann viscometers are standard instruments for determination of viscosity of drilling fluids containing bentonite, palygorskite or sepiolite.

The suspensions were prepared according to the API specifications by adding certain amounts of clay to distilled water. The clays were disaggregated with an ultrasonic probe for $20 \mathrm{~s}$ prior to stirring with a Hamilton Beach ${ }^{\circledR}$ mixer (see below). 1\%, 3\%, 5\% and 6.42\% w/v suspensions were prepared. The $6.42 \%$ suspension corresponds to the concentration suggested for industrial drilling fluids (API 13A, 1993). The suspensions were stirred for 20 minutes at $11000 \mathrm{rpm}$ and were left to age for 16 hours. After aging the suspensions were stirred again for $5 \mathrm{~min}$ before determination of rheological properties. The measurements were carried out at $\mathrm{pH} 8$. For all samples we constructed complete rheograms (plots of shear rate $v s$ shear stress). No modeling of the rheological curves was attempted using any of the rheological models shown in Figure 1.

\section{Results}

\subsection{Mineralogy}

Representative XRD traces of the palygorskite rich samples are shown in Figure 2. The clays consist mainly of palygorskite, smectite, serpentine and quartz. Minor amphibole and sepiolite are present in places. Quartz is biogenic and is related with diatom frustules. The mineralogical composition of the clays varies between palygorskite-free and smectite-free samples. The position of the 060 diffraction maximum is 1.51-1.52 $\AA$, suggesting either the presence of di-trioctahedral phyllosilicates or Fe-rich phases (the 060 diffraction maximum of nontronite is $1.52 \AA$, Moore and Reynolds, 1997). Note that the diffraction maximum at $1.535 \AA$ belongs to serpentine and indeed it is more intense in trace $b$ which is richer in serpentine. Recent FTIR data of palygorskite-free, smectite bearing samples clearly prove the existence of nontronite (data not shown). Briefly the FTIR spectra are characterized by $\mathrm{OH}$-stretching band at $3548 \mathrm{~cm}^{-1}$ and $819 \mathrm{~cm}^{-1}$ (FeFeOH stretching and bending respectively), the existence of a $\mathrm{Si}-\mathrm{Fe}-\mathrm{O}$ band at $492 \mathrm{~cm}^{-1}$ and the lack of the dominant $\mathrm{OH}$-bend- 


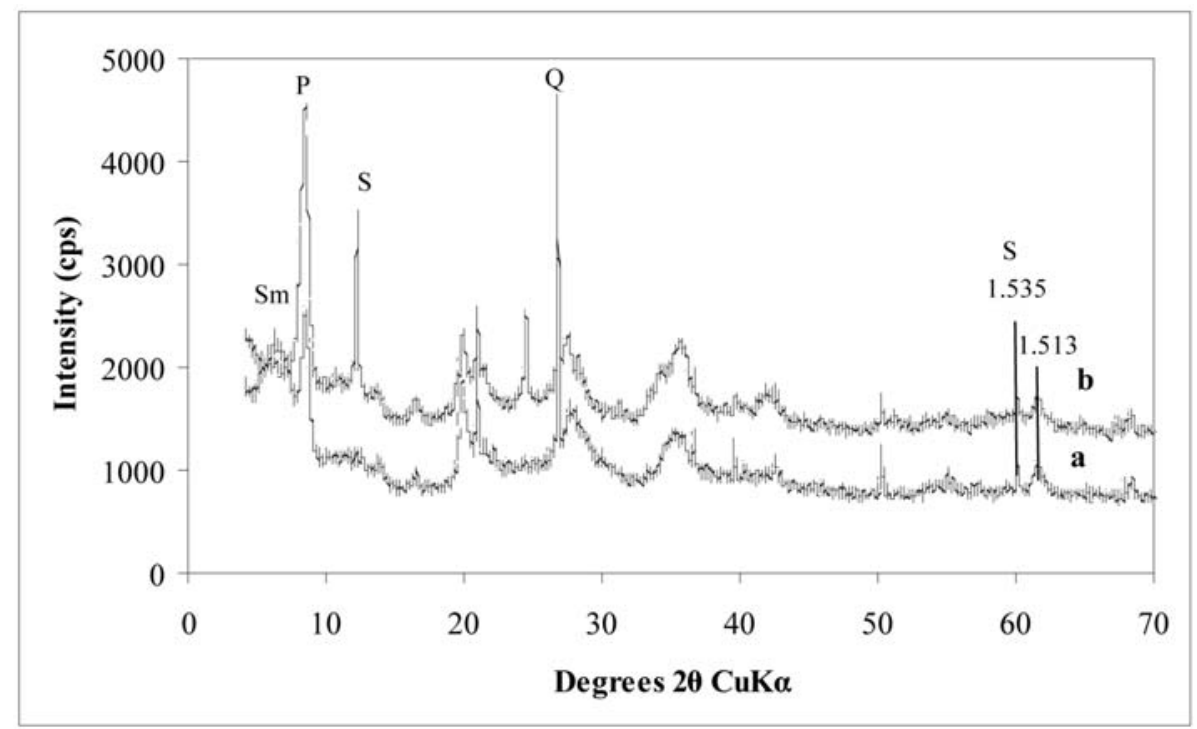

Fig. 2: Representative XRD traces of the palygorskite rich clays from the Ventzia basin. a) Smectite-bearing palygorskite clay, b) Smectite-free palygorskite clay. $\mathrm{P}=$ palygorskite, $\mathrm{Sm}=$ smectite, $\mathrm{S}=$ serpentine, $\mathrm{Q}=$ quartz .

Table 2. Rheological properties of the different clay suspensions (according to API 13A, 1993)

\begin{tabular}{|l|l|c|c|c|c|c|}
\hline \multirow{2}{*}{ Type of clay } & \multirow{2}{*}{ Rheological properties } & \multicolumn{5}{|c|}{ Suspension concentration } \\
\cline { 2 - 7 } & $\mathbf{1 \%}$ & $\mathbf{3 \%}$ & $\mathbf{5 \%}$ & $\mathbf{6 . 4 2 \%}$ & $\mathbf{6 . 4 2 \%}+\mathbf{1 M} \mathbf{~ N a C l}$ \\
\hline \multirow{2}{*}{$\begin{array}{l}\text { Clay with } \\
\text { smectite + paly- } \\
\text { gorskite }\end{array}$} & Apparent viscosity (cp) & 1.13 & 3.13 & 8.13 & 15 & 6.25 \\
\cline { 2 - 7 } & Plastic viscosity (cp) & 1 & 1.75 & 4 & 2.5 & 4.5 \\
\cline { 2 - 7 } & Yield point (Pa) & 0 & 0.25 & 2.5 & 7 & 1.5 \\
\hline \multirow{3}{*}{$\begin{array}{l}\text { Clay with paly- } \\
\text { gorskite }\end{array}$} & Apparent viscosity (cp) & 1.88 & 4.88 & 17.75 & 23.75 & 24.5 \\
\cline { 2 - 7 } & Plastic viscosity (cp) & 1.25 & 1.75 & 2.25 & 2.25 & 6 \\
\cline { 2 - 7 } & Yield point (Pa) & 0.1 & 1.75 & 14 & 13.9 & 10 \\
\hline
\end{tabular}

ing band at $670 \mathrm{~cm}^{-1}$ characteristic for trioctahedral phyllosilicates. The Si-Fe-O band at $492 \mathrm{~cm}^{-1}$ is indicative of tetrahedral $\mathrm{Fe}$. It is therefore concluded that the predominant smectite present is a Ferich smectite dioctahedral smectite (nontronite) not a trioctahedral smectite (saponite).

\subsection{Rheological properties}

The rheological properties of the representative clays containing palygorskite and palygorskite + smectite are listed in Table 2. In the electrolyte free suspensions viscosity and yield point increases with increasing clay content. Palygorskite suspensions in general develop higher apparent viscosity and yield point than their smectite-bearing counterparts, but the plastic viscosities of the two clay suspensions are comparable (Table 2). In the smectite-bearing clay plastic viscosity decreases for suspension concentration $6.42 \%$. In electrolyte bearing suspensions the two clays display different be- 


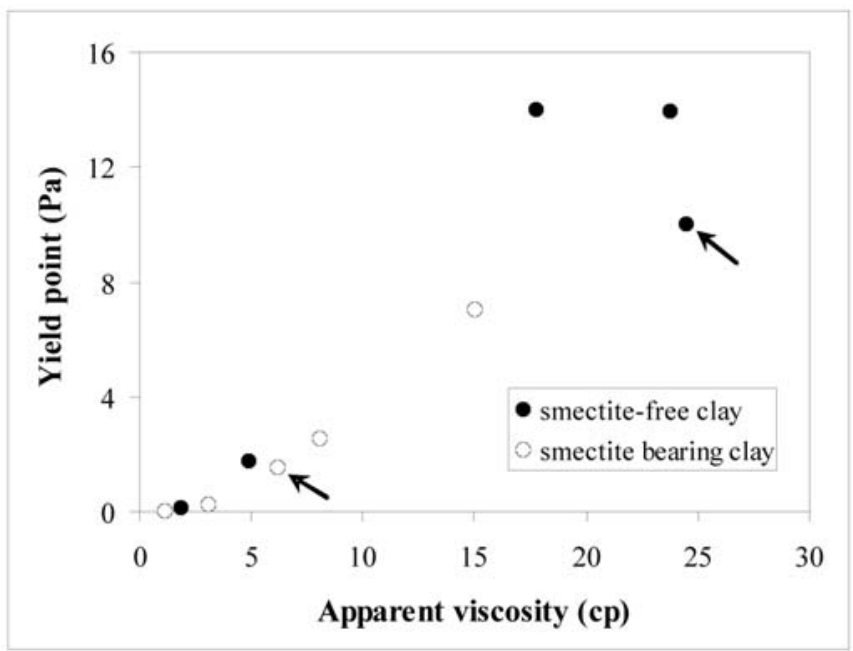

Fig. 3: Relationship between apparent viscosity and yield point for the different clay suspensions. The arrows indicate $\mathrm{NaCl}$ suspensions with concentration $6.42 \%$.

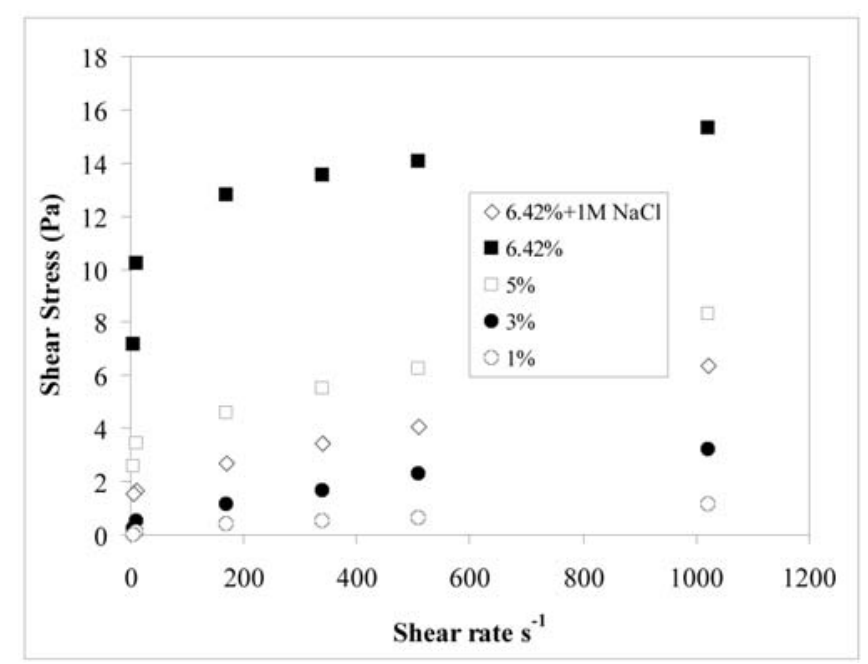

Fig. 4: Rheograms of smectite-bearing clay suspensions with different concentrations. See text for discussion.

haviour. Palygorskite suspensions are not affected or their rheological properties are improved (e.g. plastic viscosity) after addition of $1 \mathrm{M} \mathrm{NaCl}$, whereas smectite-bearing suspensions flocculate and display inferior rheological properties (Table 2).

Therefore palygorskite suspensions are affected to a lesser degree from the presence of electrolytes in accordance with previous reports (Galan, 1996). Finally, yield point is correlated with apparent viscosity but not with plastic viscosity (Fig. 3). This relationship is better expressed for smectite bearing suspensions than for pure palygorskite suspensions. 


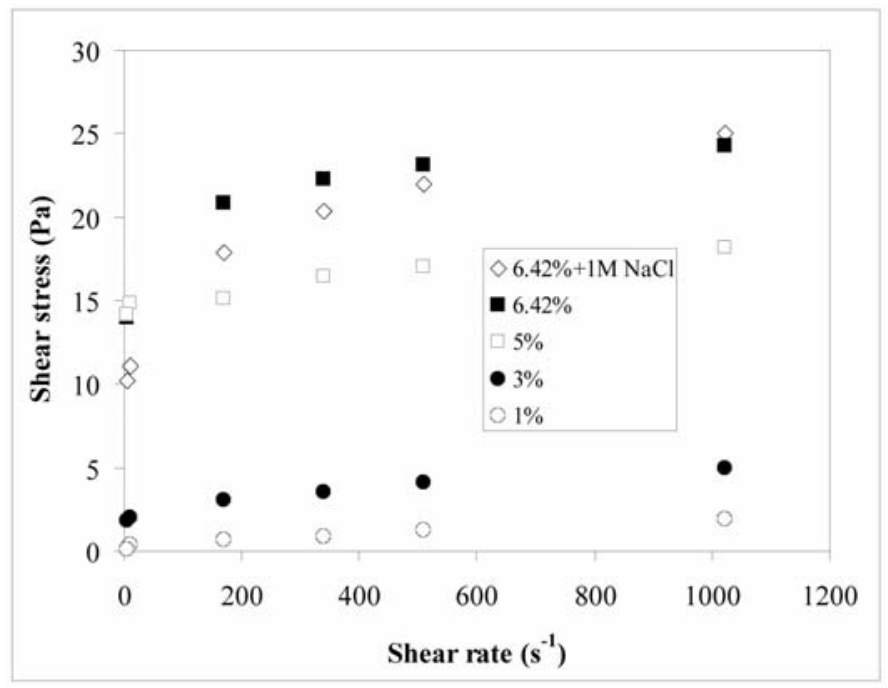

Fig. 5: Rheograms of palygorskite clay suspensions with different concentrations. See text for discussion.

Representative rheograms of smectite-bearing clay suspensions with different concentrations are shown in Fig. 4. The XRD trace of this clay sample is shown in Figure 2a. Electrolyte-free clay suspensions have essentially Newtonian characteristics at $1 \%$ concentration (yield point is not observed), which become Bingham plastic for 3\% concentration (development of yield point) and Herschel Buckley (shear thinning behaviour with yield point) at higher concentrations. The clay concentration affects both flow resistance (viscosity) and yield point (Table 2, Fig. 4). Both increase with increasing clay concentration. Addition of electrolyte affects the behaviour of the suspension which displays Bingham plastic characteristics. Also the rheogram of the $6.42 \%$ suspension with $1 \mathrm{M}$ $\mathrm{NaCl}$ is between the suspensions with concentration of 3 and $4 \%$ clay. Addition of electrolyte decreases both the viscosity and the yield point of the clay suspensions.

Representative rheograms of suspensions of the palygorskite clay with different concentrations are shown in Figure 5. The XRD trace of this clay sample is shown in Figure 2b. The flow is essentially Newtonian for suspension concentration 1\%, becoming Herschel-Bulckley type at higher concentrations (Fig. 5). Bingham flow behaviour was not observed at any concentration. Viscosity and yield point increases with increasing suspension concentration, the latter being essentially constant at concentrations higher than $5 \%$. Addition of $1 \mathrm{M} \mathrm{NaCl}$ to the $6.42 \%$ palygorskite suspension does not affect its rheological characteristics significantly. The flow behaviour is described better by the Herschel-Bulkley model, but the plastic viscosity and the yield point are greater than the electrolyte-free suspension. In summary the palygorskite suspensions display better rheological characteristics than their smectitebearing counterparts and they are affected to a lesser degree by the addition of electrolytes.

\section{Discussion}

The flow behaviour of suspensions containing palygorskite and mixture of smectite and palygorskite displays some similarities and some important differences. The similarities include the increase of viscosity and yield point with increase of suspension concentration and the Newtonian flow behaviour for suspension concentration $1 \%$. The differences include response in the addition of electrolyte 
and the flow characteristics of the suspensions and are attributed to different structures of the suspended clay particles. This in turn is due to the different morphological and structural characteristics of smectite and palygorskite.

Palygorskite forms fibrous crystals often larger than $2 \mu \mathrm{m}$ in size (Jones \& Galan, 1988), whereas smectites form flakes usually smaller than $0.5 \mu \mathrm{m}$ (Grim \& Güven, 1978; Christidis, 1995). Although, nontronite often form ribbon-like crystals (Grim \& Güven, 1978; Christidis et al., 1995), their size is considerably smaller than palygorskite fibres. Palygorskite crystals have low layer charge and the viscosity of their suspensions is due to the formation of networks of aggregated fibres. These networks are also responsible for the development of yield point especially at higher clay concentrations. In contrast smectite crystals at this $\mathrm{pH}$ form edge-to-edge band-like aggregates rather than card-house structures (Brandenburg and Lagaly, 1988). These aggregates are responsible for the development of viscosity in smectite suspensions.

Palygorskite suspensions develop different flow characteristics than their smectite-bearing counterparts. The rheograms are described by the Herschel-Bulkley model, even at suspension concentrations as low as 3\%. This model indicates complex linkages between palygorskite fibres even at low concentrations, at which smectite-bearing clays display Bingham-plastic behaviour. The fact that smectite-bearing suspensions develop Herschel-Bulkley flow characteristics at higher concentrations is in accordance with the complex particle associations and formation of networks between palygorskite fibers.

The different rheological behaviour of the smectite-bearing suspensions in electrolyte bearing suspensions is due to the compression of the diffuse double layers of the smectite particles. In fact the decrease of the rheological properties reflects the presence of smectite. Compression of the double layers causes flocculation of the smectite particles, thus decreasing viscosity. Moreover in cases in which smectite quasicrystals form networks with palygorskite fibers, formation of larger aggregates of smectite crystals is expected to weaken the palygorskite-smectite neworks leading to lower yield points. On the other hand, palygorskite has lower layer charge and is expected to develop less extended diffuse double layers, the thickness of which is not affected significantly by the presence of electrolytes. Therefore viscosity and yield point are not affected by the presence of electrolytes. Similar results were obtained from sepiolite suspensions after addition of electrolytes (data not shown). It is not known if the addition of bivalent electrolytes (e.g. $\mathrm{CaCl}_{2}$ or $\mathrm{MgCl}_{2}$ ) will affect the rheological properties of the palygorskite suspensions in a similar manner.

In summary the palygorskite from the Ventzia Basin, Grevena, develops suspensions of high viscosity which meet the API specifications even at concentration of 5\%. These suspensions are not affected by the addition of electrolytes. In this manner they perform better than bentonites in seawater based drilling fluids.

\section{Acknowledgments}

The authors would like to thank Geohellas S.A. for the supply of palygorskite samples from their deposits in Grevena area.

\section{References}

API Specifications 13A 1993. Specification for Drilling Fluid Materials. American Petroleum Institute.

Brandenburg, U. \& Lagaly, G. 1988. Rheological properties of sodium motnmorillonite dispersions. Appl. Clay Sci., 3, 263-279. 
Christidis, G.E. 1995. Mechanism of illitization of bentonites in the geothermal field of Milos Island, Greece. Evidence based on mineralogy, chemistry, particle thickness and morphology. Clays Clay Miner., 43, 567-594.

Christidis, G., Scott, P.W. and Marcopoulos, T. 1995. Origin of the bentonite deposits of Eastern Milos, Aegean, Greece: Geological, Mineralogical and Geochemical evidence. Clays Clay Miner., 43, 6377.

Galan, E. 1996. Properties and applications of palygorskite-sepiolite clays. Clay Miner., 31, 443-453.

Grim, R.E. and Güven, N. 1978. Bentonites. Geology, mineralogy, properties and uses. Elsevier, Amsterdam, 143-155.

Heath, D. and Tadros, T.F. 1983. Influence of $\mathrm{pH}$, electrolyte and poly(vinyl alcohol) addition on the rheological characteristics of aqueous dispersions of sodium montmorillonite. J. Colloid Interf. Sci., 93, 307-319.

Hiemenz, P.C. and Rajagopalan, R. 1997. Principles of colloid and surface chemistry, $3^{\text {rd }}$ edition. New York: Taylor and Francis.

Jones, B.F. and Galan, E. 1988. Sepiolite and palygorskite. In: Bailey S.W. (ed.): Hydrous Phyllosilicates. Rev. Mineral., 19, MSA 631-674.

Kastritis, I.D., Kacandes, G.H. and Mposkos, E. (2003): The palygorskite and Mg-Fe-smectite clay deposits of the Ventzia basin, western Macedonia, Greece. In: Eliopoulos, D. et al., (eds): Mineral exploration and sustainable development, Millpress, Rotterdam, 891-894.

Keren, R. 1988. Rheology of aqueous suspension of sodium/calcium montmorillonite. Soil Sci. Soc. Am. $J ., 52,924-928$.

Keren, R. 1989. Effect of clay charge density and adsorbed ions on the rheology of montmorillonite suspension. Soil Sci. Soc. Am. J., 53, 924-928.

Lagaly, G. 1989. Principles of flow of kaolin and bentonite dispersions. Appl. Clay Sci., 4, 105-123.

Lyckham, P.F. and Rossi, S. 1999. The colloidal and rheological properties of bentonite suspensions. $A d v$. Colloid Interface Sci., 82, 43-92.

Moore, D.M. and Reynolds, R.C. Jr. 1997. X-ray diffraction and the identification and analysis of clay minerals, $2^{\text {nd }}$ edition. Oxford: Oxford University Press.

Murrey, H.H. 2007. Applied Clay Mineralogy/Developments in Clay Science 2/. Elsevier, Amsterdam, 180 pp.

Neaman, A. \& Singer A. 2000. Rheological properties of aqueous suspensions of palygorskite. Soil Sci. Soc. Am. J., 64:427-436.

Neaman, A. \& Singer A. 2004. Possible use of the Sacalum (Yucatan) palygorskite as drilling muds. Appl. Clay Sci., 25, 121-124.

Permien, T. and Lagaly, G. 1995. The rheological and colloidal properties of bentonite dispersions in the presence of organic compounds. V. Bentonite and sodium montmorillonite and surfactants. Clays Clay Miner., 43, 229-236. 